\title{
IV.-RESEARCH.
}

\section{EXPERIMENTS ON THE ASSOCIATION OF IDEAS.}

\section{By James MoKeen Catteri, Ph.D.}

The Association of Ideas has been a favourite subject with psychologists from Aristotle on, yet the results have not been very definite from the scientific point of view. An importent paper by Mr. Galton ' first applied experimental methods to the subject, and put it in a way where scientific advance was possible. Professor Wundt at once saw the importance of this work, and took it up in his leborstory with improved apparatus and methods." Nothing further has, however, been published on the subject, which is a pity, as experimental psychology seems to have its most hopeful outlook in this direction.

Experiments I described in a paper contribated to MIND, Nos. 42-4, on "The Time taken up by Cerebral Operations," showed that about $\frac{2}{5}$ sec. was needed to see and name a word. When the physiological factors and the time taken up in seeing the word were eliminated, it was found that about $\frac{1}{10}$ sec. was epent in finding the name belonging to the printed symbol. The time was longer for letters, which we do not read as often as words, and still longer (about 1 sec.) for colours and pictures. I called the time pessing, while the motor expression was being found, a 'Will-time'. The process is, however, largely automatic, and consists in carrying out an association previously formed between the concept and the expression. There is no break between sach a process and the other processes I am about to describe.

I.

If an object is named in a foreign instead of in one's native language, the association between concept and expression is less intimate and takes up more time. It is an open question as to how far concepts are formed without the aid of words, and it is not evident what mental process takes place when an object is named in a foreign language, it depending, of course, on the familiarity of the language. It need scarcely be said that we know almost nothing as to the physical basis of memory and thought; we may hope that psychometric experiments, such as I am about to describe, will contribute something toward the study of this subject. In the paper above mentioned I showed how we can determine the time it takes to see and name the picture of an object; in like manner the time we need to name

1 Brain, 1879 ; cp. Mrvd, iv. 551.

= Physivlogieche Psychologie, c. xvi ; Philosophische Studion, i. 1. 
the picture in a foreign lenguage can be messured. I must refer the reader to that paper for a detailed account of apparatus and methods. $001 \mathrm{sec}$. is taken as the unit of time, $\sigma$ being used as its symbol. B (Dr. G. O. Berger) and C (the writer) are the two subjects; after these designations there is given the average time taken in all the experiments made, and the mean variation of these measurements from the average; after this is given a second average and mean variation, found by dropping the most irregular times in accordence with the method I have described. ${ }^{1}$ The number of experiments made on each subject is given in parenthesis. The experiments were made at Ireipsic during the first half of the year 1885.

I give first the time it took the subjects to recognise the pictures of twenty-six familiar objects, and name them in a foreign language- $\mathrm{B}$ in English, $\mathrm{C}$ in German.

\section{Pictures named in Foreign Language (78). \\ $\begin{array}{llllllllll}\text { B } & 649 & 104 & 632 & 49 & \text { C } & 694 & 87 & 682 & 49\end{array}$}

It has been shown ${ }^{2}$ that B took 477, C 545\% to see and name these same pictures in their native languages. B consequently needed $172, \mathrm{C} 149 \sigma$ in addition to find the name in a foreign language. C talks German readily, B English less so. These should be compared with other experiments I have made showing that the rate at which a person can read a foreign language is proportional to his familiarity with the language.'

We go a step further when a word must be translated from one language into another. The mentel operation is again obscure, the processes of translating and naming not being sharply defined; but if we subtract the time it takes to see and name a word from the time it takes to see a word, to translate it into a foreign language and name it, we get approximately the time of translation. This tine I give for translating from a foreign into the native language, and in the reverse direction. I have subtracted the time it takes the subjects to see and name words (B $390, \mathrm{C} 428 \sigma$ ), and the mean variation (B 28, C 20 ; in the corrected series, B 19, C 13s).

$$
\begin{aligned}
& \text { English-German: Short (Common) Words (78). } \\
& \begin{array}{lllllllll}
\text { B } & 240 & 77 & 199 & 36 & \text { C } & 258 & 59 & 237
\end{array}
\end{aligned}
$$

1 MIND, xi. 289. It will be noticed that the corrected averages are usually smaller than the averages from all the determinations; this is because the subject found difficulty in a few crses. The uncorrected value gives the average time taken up by associations; the corrected average more nearly the time usually taken up by associations.

2 MIND, xi. 533.

3 Phil. Studien, ii. 635; A batract in MIND, xi. 63. I hope shortly to print an acconnt of experiments showing the increasing rapidity with which the clusses of a German gymnasium can read Latin. 


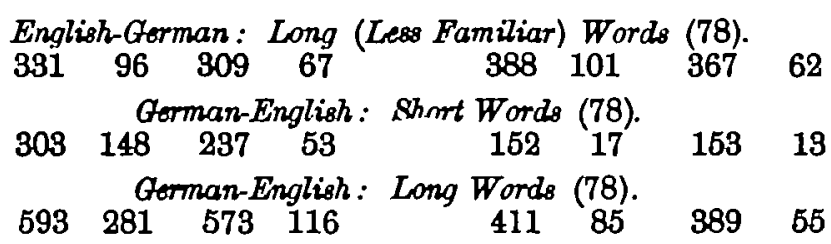

These numbers show that foreign languages take up much time even after they have been learned, and may lead us once more to weigh the gain and loss of a polyglot mentel life.

II.

$\Lambda$ great part of our time is spent in calling to mind things we already know. Memory is no transcendental process outside of space and time; this paper shows just how much time it tekes to remember, and we have every reason to believe that the time passes while certain changes in the brain call forth other changes. I give below the time it took $B$ and $C$ to remember certein facts, examples of the necessary associstions with which the mind is continually busy. A well-known city was given, and the subject nemed the country in which it is situated; a month was given, and the season to which it belongs was named, and in like manner the preceding or following month; an eminent author was given, and the subject named the lenguage in which he wrote; a distinguished man, and his calling was named. In the last two cases below, the subject respectively added and multiplied numbers of one place. At first sight this mental operation may seem to consist of a mathematical calculation, and to be altogether different from the others; it is however not unlike them, being essentially an act of memory.

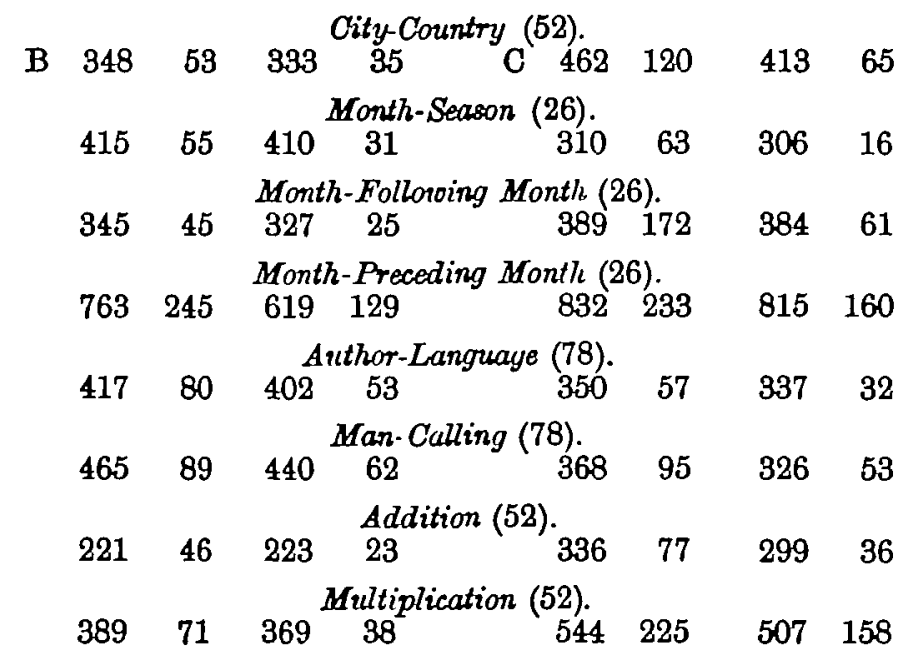


The mentel processes considered above are by no means invented for the sake of experiment, but are such as make up a considerable part of life. We see that it took the subjects $\frac{9}{5}$ to $\frac{4}{5}$ sec. to call to mind facts with which they were familiar. The times needed in the different cases are of interest. The time of addition was the shortest of all ; B needed 168, C 208\% longer to multiply than to add; it took twice as long to call to mind the foregoing as the following month. It will be noticed that the times of the two subjects correspond closely (the everage time in the eight examples given is 420 o for $B, 436$ for $C$ ); the differences of time in the several cases are explained by the character and pursuits of the subjects, and in turn throw light back upon these. For example, B is a teacher of mathematics, $C$ has busied himself more with litersture; C knows quite as well as $B$ that $5+7=12$, yet he needs $\frac{1}{10}$ sec. longer to call it to mind; $\mathbf{B}$ knows quite as well as $C$ that Dante was a poet, but needs $\frac{1}{10}$ sec. longer to think of it. Such experiments lay bare the mentel life in a way that is startling and not always gratifying.

The numbers given are the averages from many measarements; the mean variation shows how greatly the separate determinations vary from the average. This variation is partly owing to changing conditions of the brain, so that the same process never takes exactly the same time; it is, however, largely due to the fact that the mental operations under the same class are not equally simple, and consequently require different times. Just as it takes less time to add 2 to 3 than to multiply 2 by 3 , so it takes less time to add 2 to 3 than to add 6 to 7 . Owing to the normal variation in the time of the same mentel process, we should not place too much reliance on a small number of measurements; it will, however, be worth our while to notice a few examples. In giving the country in which the city is situated, as average of three trials, both $B$ and $C$ took the shortest time for Paris $(212,278 \sigma$ ), and the longest time for Geneva (403, 485o). In giving the language in which an author wrote, as average of the three trials, B took the shortest time for Luther (227) and Goethe (265), and the longest for Aristotle (591) and Bacon (565); C took the shortest time for Plato (224) and Shakespeare (258), the longest for Chancer (503) and Pleutus (478). In the case of Luther B took 244, in the case of Goethe 102 $\sigma$ less time than $\mathrm{C}$; in the case of Shakespeare $\mathrm{C}$ took $186 \sigma$ less time than B. It should be borne in mind that $\mathrm{B}$ is a German, $\mathrm{C}$ an American. In giving the calling of eminent men the order was as follows, toe shortest times being placed first:-B-Poet (355), Warrior, Historian, Philosopher, Artist, Reformer, Man of Science (657) ; C-Poet (291), Artist, Historian, Werrior, Philosopher, Reformer, Man of Science (421). With both subjects Poet comes first and Man of Science last. It is easier to think of Homer as a poet than of Darwin as a man of science. 
III.

In the experiments so far considered a question was asked which admitted but one answer : the association was necessary, and the interval passing while it was being formed might be called a 'Recollection-time'. A question can, however, be so arranged that beside the act of recollection a certain choice as to the answer must be made, and in this case a little more time is needed. Below is given the inverse of several of the cases we have considered; a country being given, some city situated in it had to be named, \&c. The last line gives the time needed to think of a work by a given author.

\begin{tabular}{|c|c|c|c|c|c|c|}
\hline & & & Country-City (26). & & & \\
\hline 400 & 72 & 357 & C 346 & 75 & 340 & 48 \\
\hline & & & Season-Month (26). & & & \\
\hline 561 & 92 & 548 & $\begin{array}{ll}36 & 435\end{array}$ & 99 & 399 & 54 \\
\hline & & & anguage-Author (78) & & & \\
\hline 663 & 200 & 702 & $110 \quad 519$ & 137 & 523 & 83 \\
\hline & & & Author-Work (26). & & & \\
\hline 1076 & 397 & 1095 & $287 \quad 763$ & 308 & 596 & \\
\hline
\end{tabular}

It will be seen that it took no longer to name a city when the country was given than the reverse; in this case there was but little choice, as there is in each country one particular city which was named almost as a matter of course. It took, however, considerably longer to name a month when the season was given and an author when a language was given than the reverse. A choice had in the former case to be made, and further, as Steinthal has before remarked, ${ }^{1}$ the mind moves more readily from the part to the whole than from the whole to the part. It will be noticed that the naming a work by a given author is one of the most difficult associations considered in this paper. As to the time taken up by the separate associations, I must again call attention to the fact that it is largely determined by accidental variation. This variation could only be eliminated by making a large number of experiments, and in this case we should no longer have the time taken up by associations in our daily life, but the minimum recollection-time, which would tend to become the same for different classes of associations as they became equally familiar. In naming a city, $C$ needed the longest time for Brussels (1042) and Pekin (1001); the shortest time for Athens (214) and Philedelphia (222), his home. In naming an author, less time was needed for English, German and Italian, where Shakespeare, Goethe and Dante at once occurred, than in the three other languages used, French, Latin and Greek. In naming a work by a given author $\mathrm{C}$ needed the

\footnotetext{
' Einleitung in die Poychologie und Sprachu issensehaft, p. 161.
} 
longest time for Chancer (Canterbury Tales 1898), Aristotle (Logic [sic] 1522), and Bacon (Novum Organum 1388); the shortest time for Milton (Paradise Last 328), Dante (Inferno 373), and Goethe (Faust 393).

IV.

We now come to consider certain classes of associations in which the mind is allowed a larger degree of liberty. The times required in eight such cases are given. A noun representing a class of objects was given and a particular example was named (riverRhine) ; a picture of an object was shown, and instead of naming the entire picture the subject was required to select some part of the object and name it (picture of a ship-sail); a concrete noun was in the same way given and a part of the object was named : both the pictures and nemes of objects were shown, and the subject seid what the thing is used for or what it does (horse-ride or trot); a substantive had to be found for an adjective (blue-sky), a subject for an intransitive (swim-fish) and an object for a transitive verb (write-letter).

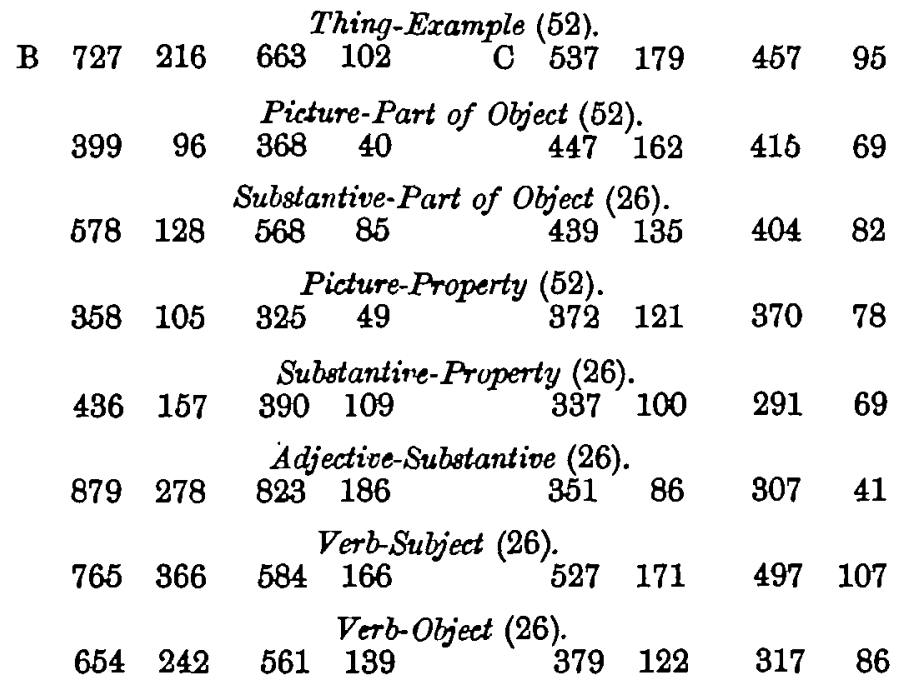

The times given need no long comment. The most difficult associations seem to be the finding of a special example when the class is given, and the subject for a verb; in both of these ceses the times needed were irregular, as is shown by the large mean variation. B took 111, C 146o longer to find a subject than to find an object for a verb, the mind moving logically in the latter direction. In identifying a particular object the mind was inclined to choose either one immediately at hand or to go back to the home of childhood. Thus out of the 52 cases $B$ thought of an object f) 
in the room $8, \mathrm{C} 20$ times; ${ }^{1}$ of objects identified with the early home B 22, C 19 times. In the other cases this was mostly impossible, but also here either a very recent or an early association was formed in all except 6 out of the 104 cases.

7.

We have lastly to consider the time it takes to form a judgment or opinion. I choose three cases in which the results could conveniently be averaged. In the first case the subject estimated the length of a line drawn horizontally on a card $10 \mathrm{~cm}$. long, 50 lines being used varying in length from 1 to $50 \mathrm{~mm}$. In the second case the subject estimated the number of short perpendicular lines on a card," the number varying between 4 and 15 . In the third case the names of two eminent men were shown, and the subject decided which of them he thought to be the greater.

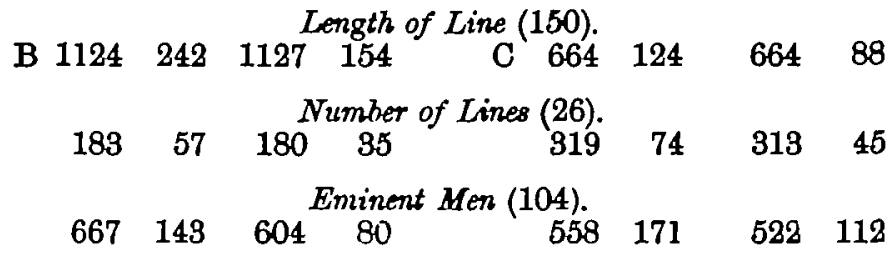

I made rather a large number of determinations with the lines, as I wished to find the ratio between the length of the line and the average error (psychophysical law), and between the error and the time taken up in coming to a decision. I think it however desirable to still further increase the number of experiments before publishing the results. In judging as to the relative greatness of eminent men, as might be foreseen, the times were shortest where the judgment was easiest, more especially if the subject had already compared the men together (Homer, Virgil). The nature of the judgments is not without interest, but can better be considered when I come to print similar experiments which I have made on a larger number of subjects.

The associations we have been considering in this paper are in their nature fixed or limited, and we have concerned ourselves chiefly with the time taken up. The conditions of the experiment can however be so arranged that one ides is allowed to suggest another somewhat as in our ordinary thinking. I shall shortly have ready experiments in this direction in which both the time and the nature of the association will be considered.

1 The experiments were made in $\mathrm{Cs}$ room.

- For experiments on the Linits of Consciousness see Cattell, Phil. Studien, iii. 94. 